
Humans Peter Baumann and Thomas R. Cech

Science 292, 1171 (2001);

DOI: $10.1126 /$ science.1060036

This copy is for your personal, non-commercial use only.

If you wish to distribute this article to others, you can order high-quality copies for your colleagues, clients, or customers by clicking here.

Permission to republish or repurpose articles or portions of articles can be obtained by following the guidelines here.

The following resources related to this article are available online at www.sciencemag.org (this information is current as of August 5, 2014 ):

A correction has been published for this article at: http://www.sciencemag.org/content/293/5528/214.2.full.html

Updated information and services, including high-resolution figures, can be found in the online version of this article at:

http://www.sciencemag.org/content/292/5519/1171.full.html

Supporting Online Material can be found at: http://www.sciencemag.org/content/suppl/2001/05/10/292.5519.1171.DC1.html

A list of selected additional articles on the Science Web sites related to this article can be found at:

http://www.sciencemag.org/content/292/5519/1171.full.html\#related

This article cites $\mathbf{3 1}$ articles, 19 of which can be accessed free:

http://www.sciencemag.org/content/292/5519/1171.full.html\#ref-list-1

This article has been cited by 408 article(s) on the ISI Web of Science

This article has been cited by 100 articles hosted by HighWire Press; see:

http://www.sciencemag.org/content/292/5519/1171.full.html\#related-urls

This article appears in the following subject collections:

Cell Biology

http://www.sciencemag.org/cgi/collection/cell_biol 
form stable antiparallel overlaps in which motors are present (24-26). It will be interesting to determine which properties are responsible for the stabilization of such antiparallel MT overlaps.

In exploring the generic steady-state patterns that could emerge from mixtures of MTs and one or two oligomeric motors of opposite directionality, we have found a limited number of patterns: radial MT structures, either asters or vortices, or networks of poles connected by aligned MTs. Using computer simulations, we found that changes in the value of many parameters did not affect the topology of the pattern, whereas changes in other parameter values did. Those parameters are potential key targets for regulation. Many complex biological structures are also collective out-of-equilibrium assemblies. In the past, they have been described mainly by attributing qualitative "functions" to some of their constituent molecules. Here, we have used kinetic parameters describing the properties and interactions of the molecules to deduce the structures produced by the ensemble.

\section{References and Notes}

1. H. Fraenkel-Conrat, R. C. Williams, Proc. Natl. Acad. Sci. U.S.A. 41, 690 (1955).

2. S. Inoue, in 40th Symposium of the Society for Developmental Biologists, S. Subtelny, P. B. Green, Eds. (Liss, New York, 1982), pp. 30-35.

3. A. M. Turing, Philos. Trans. R. Soc. London Ser. B 237, 37 (1952).

4. I. Prigogine, G. Nicolis, J. Chem. Phys 46, 3542 (1967).

5. B. L. Goode, D. G. Drubin, G. Barnes, Curr. Opin. Cell Biol. 12, 63 (2000).

6. S. L. Rogers, V. I. Gelfand, Curr. Opin. Cell Biol. 12, 57 (2000).

7. W. Saunders, V. Lengyel, M. A. Hoyt, Mol. Biol. Cell 8, 1025 (1997).

8. C. E. Walczak, I. Vernos, T. J. Mitchison, E. Karsenti, R. A. Heald, Curr. Biol. 8, 903 (1998).

9. D. J. Sharp et al., Mol. Biol. Cell 11, 241 (2000).

10. F. Nédélec, T. Surrey, A. C. Maggs, S. Leibler, Nature 389, 305 (1997).

11. R. J. Stewart, J. P. Thaler, L. S. Goldstein, Proc. Natl. Acad. Sci. U.S.A. 90, 5209 (1993).

12. The kinesin construct contains the $\mathrm{NH}_{2}$-terminal 401 amino acids of Drosophila kinesin and a $\mathrm{COOH}$-terminal biotinylation domain (27). GST-Ncd consists of the $\mathrm{COOH}$-terminal 506 amino acids of Drosophila Ncd fused to an $\mathrm{NH}_{2}$-terminal GST tag (11). Both proteins were expressed in bacteria and purified as described (28). The motors were flash-frozen in liquid ethane and stored in liquid nitrogen. Fluorescein-labeled streptavidin was from Molecular Probes, monoclonal anti-GST was purified from mouse ascites (Sigma), and tubulin was purified from cow brain. Oligomeric motor complexes were made immediately before the experiment by mixing biotinylated kinesin and streptavidin or GSTNcd and anti-GST, resulting in complexes of $8(10)$ or 8 to 12 motors, respectively. For the size determination of Ncd complexes by gel filtration, ultracentrifugation, and fluorescence correlation spectroscopy, and for the preparation of polarity-marked MT seeds, see supplementary material (15). Self-organization experiments were performed essentially as described $(10,28)$, with agarose and bovine serum albumin-coated glass cover slips for microscopy to avoid motor-mediated gliding of MTs on the glass surface. Final buffer concentrations in experiments with Ncd complexes and kinesin complexes were typically $800 \mathrm{mM}$ glycerol, $140 \mathrm{mM}$ glutamate, $20 \mathrm{mM}$ Pipes, $12.5 \mathrm{mM}$ imidazole, $12.5 \mathrm{mM} \mathrm{KCl}, 4.0 \mathrm{mM}$ $\mathrm{MgCl}_{2}, 0.5 \mathrm{mM}$ EGTA, $3.0 \mathrm{mM}$ ATP, $1.4 \mathrm{mM}$ GTP, 2.5 $\mathrm{mM}$ phosphoenolpyruvate, pyruvate kinase (350 U $\mathrm{ml}^{-1}$; Sigma, P-7768) (pH 6.9), 1.0 mM mercaptoetha- nol, $0.15 \mathrm{mM}$ dithiothreitol, and $2.6 \mu \mathrm{M}$ paclitaxel (Molecular Probes). [For a discussion of the effect of paclitaxel on self-organization, see supplementary material (15).] Final concentrations in experiments with one motor complex were similar to those with two motors [for details, see (28)]. Immediately after the final mixing steps, samples of $1.3 \mu \mathrm{l}$ were warmed on the microscope to $30^{\circ} \mathrm{C}$ (to start MT polymerization), maintained at this temperature throughout the experiment, and observed by dark-field and fluorescence microscopy on a Zeiss Axiovert 10 with a digital image recording system (Sony SSC M370CE charge-coupled device, Power Mac G3 and Scion Image 1.62).

13. The structures shown in Fig. $2 \mathrm{~A}$ were stable for at least 1 hour, then protein aggregation started to become visible. We also confirmed by simulations that vortices and asters are stable for at least 1 hour.

14. F. Nédélec, T. Surrey, A. C. Maggs, Phys. Rev. Lett. 86, 3192 (2001)

15. Supplementary data are available on Science Online at www.sciencemag.org/cgi/content/full/292/ 5519/1167/DC1 and at www.embl-heidelberg.de/ Externallnfo/karsenti/self.

16. F. Nédélec, thesis, Université Paris XI, Orsay (1998). 17.

18. When the processivity was reduced to one step before unbinding, asters stopped forming, and this could no longer be compensated in the range of parameter variations studied here. Indeed, this result suggests that the oligomeric Ncd complex used in the experiments is considerably processive-in contrast to dimeric Ncd, which is not (29). However, small numbers of Ncd molecules, when acting cooperatively, can be processive (30). This is probably the case for our construct, which consists of 8 to $12 \mathrm{Ncds}$ (15). Similarly, this might also explain why $p_{\text {off,end }}$ of the Ncd complex appears to be low.

19. It is surprising that in experiments with kinesin, the formation of asters as compared with vortices is observed when the kinesin concentration is changed (Fig. $2 \mathrm{~A})$, whereas in simulations, this transition in response to a change in density only is not observed (Fig. 4A). This discrepancy could be due to the increase in effective residence time at MT ends of kinesin complexes with increasing motor concentration. This concentra- tion dependence could arise from crowding and aggregation effects that occur when the motors become strongly locally concentrated (Figs. 1 and 2). Such a dependence between parameters is not accounted for in the minimal model used for the simulations. We saw the same behavior of kinesin in experiments where both motors-kinesin and Ncd-were present. The networks transformed to a mixture of Ncd asters and kinesin vortices when the motor/MT ratio was decreased, whereas in simulations the network transformed to a mixture of asters of opposite polarity. Again, this can be explained by assuming that kinesin's off-rate from MT ends is concentration-dependent. These results indicate that the experimentally observed transitions in Fig. 2A from $b$ to $C$, and in Fig. 2B from a to $C$, correspond to simulated transitions in Fig. 4, A and C, from bottom left to top right.

20. M. Sleigh, The Biology of Protozoa (Arnold, London, 1973).

21. R. Heald et al., Nature 382, 420 (1996)

22. T. J. Mitchison, Philos. Trans. R. Soc. London Ser. $B$ 336, 99 (1992).

23. A. A. Hyman, E. Karsenti, Cell 84, 401 (1996).

24. N. R. Barton, A. J. Pereira, L. S. Goldstein, Mol. Biol. Cell. 6, 1563 (1995)

25. K. E. Sawin, T. J.Mitchison, Proc. Natl. Acad. Sci. U.S.A. 92, 4289 (1995).

26. D. J. Sharp et al., J. Cell Biol. 144, 125 (1999).

27. T. Surrey et al., Proc. Natl. Acad. Sci. U.S.A. 95, 4293 (1998).

28. F. Nédélec, T. Surrey, Methods Mol. Biol. 165, 213 (2000).

29. I. M. Crevel, A. Lockhart, R. A. Cross, J. Mol. Biol. 273, 160 (1997).

30. M. J. deCastro, C. H. Ho, R. J. Stewart, Biochemistry 38, 5076 (1999).

31. We thank L. S. Goldstein for the GST-N195 plasmid; A. J. Ashford, A. Desai, R. Tournebize, and H. Wilhelm for unlabeled and labeled tubulins; D. N. Drechsel and $M$. Groves for help with the size determination of the Ncd complex; and A. C. Maggs for help with the simulations.

\title{
Pot1, the Putative Telomere End-Binding Protein in Fission Yeast and Humans
}

\author{
Peter Baumann and Thomas R. Cech*
}

\begin{abstract}
Telomere proteins from ciliated protozoa bind to the single-stranded G-rich DNA extensions at the ends of macronuclear chromosomes. We have now identified homologous proteins in fission yeast and in humans. These Pot1 (protection of telomeres) proteins each bind the G-rich strand of their own telomeric repeat sequence, consistent with a direct role in protecting chromosome ends. Deletion of the fission yeast pot $1^{+}$gene has an immediate effect on chromosome stability, causing rapid loss of telomeric DNA and chromosome circularization. It now appears that the protein that caps the ends of chromosomes is widely dispersed throughout the eukaryotic kingdom.
\end{abstract}

Telomeres, the protein-DNA complexes at chromosome ends, protect chromosomes from degradation and end-to-end fusion, and they

Howard Hughes Medical Institute, Department of Chemistry and Biochemistry, University of Colorado, Boulder, CO 80309, USA.

*To whom correspondence should be addressed. Email: thomas.cech@colorado.edu serve as substrates for extension by telomerase. The telomeric DNA terminates with a singlestranded overhang of the G-rich strand in ciliated protozoa (1), yeast $(2,3)$, and mammalian cells (4-6). In budding yeast, the $\mathrm{Cdc} 13$ protein binds to this single-stranded DNA, protecting the chromosome end $(7,8)$ and recruiting telomerase (9). In the hypotrichous ciliate Oxytricha nova, an $\alpha-\beta$ protein heterodimer 
binds specifically to the single-stranded telomeric DNA (10-12) to form a ternary complex (13), the crystal structure of which has been solved (14). Euplotes crassus, another hypotrich, uses an $\alpha$ subunit but apparently no $\beta$ subunit (15). These yeast and ciliate end-binding proteins have no obvious sequence similarity to each other, and no homologs have been reported in distant species such as mammals. Indeed, the t-loop DNA structure that can form at the ends of mammalian chromosomes (16) might have been thought to obviate the need for an end-binding protein.

Database searching has now revealed that the Schizosaccharomyces pombe open reading frame (ORF) SPAC26H5.06 contains a region of limited similarity to the $\alpha$ subunits of telomere proteins from Oxytricha and other ciliates (Fig. 1A). Conservation is most apparent in a region of about 120 amino acids near the $\mathrm{NH}_{2}$ termini of the proteins (Fig. 1B), where the $S$. pombe and $O$. nova sequences share $19 \%$ identity and $40 \%$ similarity. This region coincides with the most highly conserved domain within the ciliate sequences $(42 \%$ amino acid identity and $61 \%$ similarity between $O$. nova and $E$. crassus). Because the ciliate telomere proteins are thought to act as protective caps at the ends of macronuclear chromosomes $(10,14)$, we named the $S$. pombe gene pot ${ }^{+}$(protection of telomeres).

To examine whether $p o t 1^{+}$is indeed involved in telomere maintenance, we constructed a heterozygous diploid $\operatorname{pot} 1^{+} /$pot $1^{-}$strain (17). Tetrad dissections revealed that the pot $1^{-}$ spores formed very small colonies compared with their pot $^{+}$sisters (Fig. 1C). This immediate phenotype is in stark contrast to that observed for strains lacking the catalytic subunit of telomerase $\left(\operatorname{trt}^{-}\right)$, which form normal-sized colonies upon sporulation (Fig. 1C) and only begin to show a growth defect after $\sim 75$ generations, when telomeres have shortened considerably (18). For $\sim 10$ generations after sporulation, pot $1^{-}$colonies contained a large number of elongated cells (Fig. 1D), most of which failed to undergo further division. DNA staining revealed a high incidence of chromo-
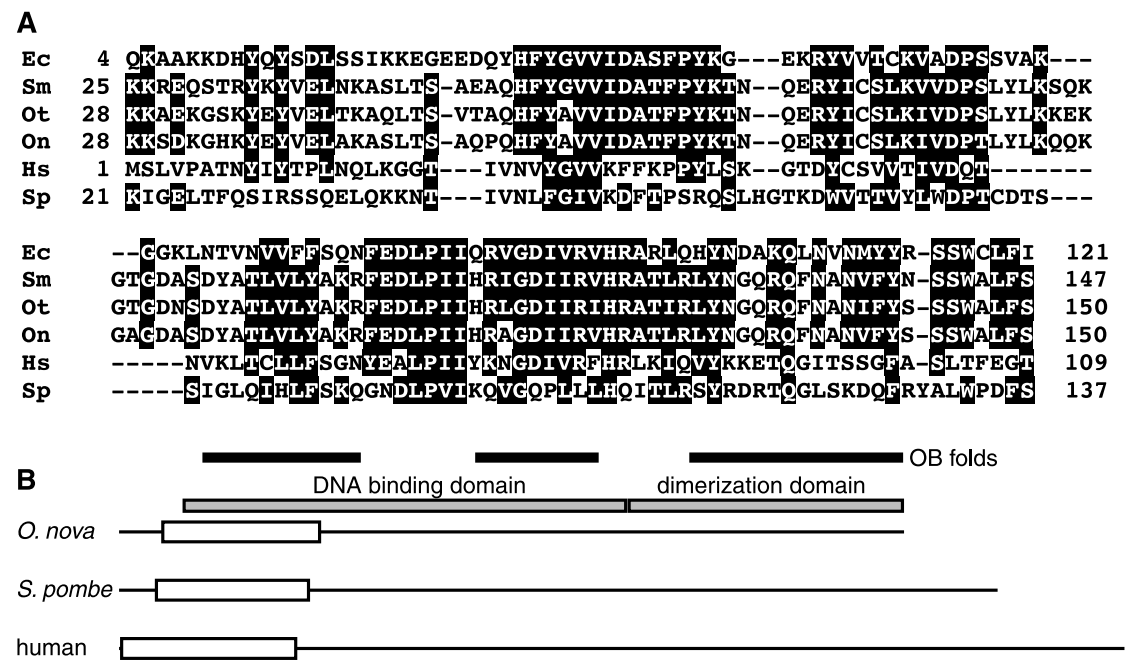

C
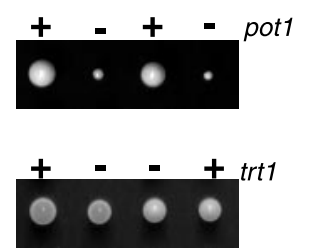

D
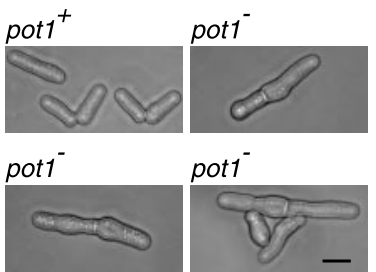

\section{E}

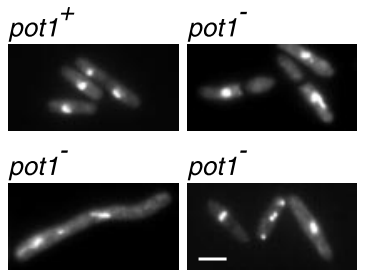

Fig. 1. Sequence comparison and morphological phenotype associated with deletion of $p o t 1^{+}$. (A) Multiple sequence alignment of the $\mathrm{NH}_{2}$-terminal regions of the $\alpha$ subunits of ciliate telomere proteins [Ec, Euplotes crassus (15); Sm, Stylonychia mytilis (39); Ot, Oxytricha trifallax (40); On, O. nova (11)] and yeast and human Pot1p (Hs, Homo sapiens; Sp, S. pombe). Starting and ending amino acid numbers are shown for each sequence. Sequences were aligned in ClustalW using the Blosum35 score table followed by minor manual adjustment. Shaded amino acids are conserved in four or more sequences. Singleletter abbreviations for amino acid residues are as follows: A, Ala; C, Cys; D, Asp; E, Glu; F, Phe; G, Gly; H, His; I, lle; K, Lys; L, Leu; M, Met; N, Asn; P, Pro; Q, Gln; R, Arg; S, Ser; T, Thr; V, Val; W, Trp; and Y, Tyr. (B) Domain structure of the $O$. nova telomere protein and yeast and human Pot1p. Positions of OB folds (14) and functional domains (23) are depicted for the O. nova telomere protein. The positions of the regions aligned in (A) are indicated by open boxes. (C) Colony morphology of $\operatorname{pot} 1^{+}, \operatorname{pot} 1^{-}, \operatorname{trt} 1^{+}$, and trt $1^{-}$after tetrad dissection and germination. (D) Phase-contrast micrographs of $p o t 1^{+}$and $p o t 1^{-}$cells 5 to 10 generations after germination. Scale bar, $5 \mu \mathrm{m}$. (E) Cells as in (D) but stained with $4^{\prime}, 6^{\prime}-$ diamidino-2-phenylindole (DAPI) to reveal chromosome segregation defect in pot1-. Scale bar, $5 \mu \mathrm{m}$.

some missegregation, often leading to daughter cells without any chromosomal DNA (Fig. 1E). These phenotypes diminished during successive restreaks; after $\sim 75$ generations, the colony and cell morphology appeared to be wild type, a development reminiscent of the emergence of survivors in strains lacking functional telomerase (18).

Deletion of pot $1^{+}$had a marked effect on telomere stability. When genomic DNA from pot $1^{-}$strains was analyzed by Southern blotting, telomeric sequences could not be detected (Fig. 2A). Using three probes that recognize distinct subregions of the telomere-asso-

\section{A}

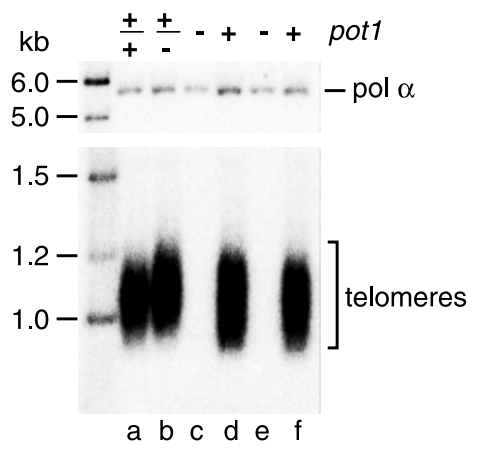

B

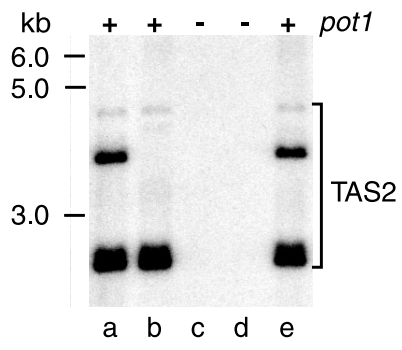

C

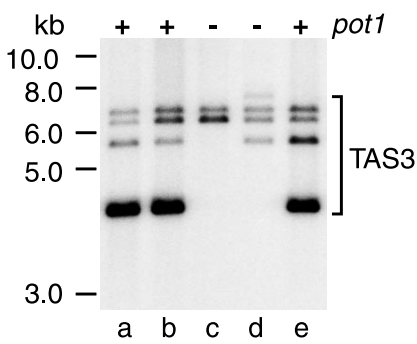

Fig. 2. Telomere phenotype in pot $1^{-}$strains. (A) Colonies from the indicated strains were used to inoculate $10 \mathrm{ml}$ of YES (yeast extract supplemented with amino acids) medium at $32^{\circ} \mathrm{C}$. Cells were grown to late log phase, and genomic DNA was prepared. After digestion of DNA $(\sim 20 \mu \mathrm{g})$ with Eco Rl, samples were subjected to $1.1 \%$ agarose gel electrophoresis, transferred to a nylon membrane, and hybridized to a telomeric probe. As a loading control, a probe against the singlecopy pol $\alpha$ gene was used. (B) Genomic DNA $(\sim 20 \mu \mathrm{g})$ was digested with Nsi I, fractionated by $0.8 \%$ agarose gel electrophoresis, transferred to a nylon membrane, and hybridized to a TAS2 probe (18). (C) The blot in (B) was stripped (34) and hybridized to a TAS3 probe. 


\section{R E P O R T S}

ciated sequence (TAS), we observed hybridprobe (Fig. 2C), but not with the more telomere-proximal TAS1 and TAS2 probes (Fig. 2B) (19). These results indicate that $\sim 5 \mathrm{~kb}$ of

One way the pot $1^{-}$cells might survive without telomeres is through chromosome circularization $(18,20)$. When DNA from ization signals with the telomere-distal TAS3 terminal sequence had been lost. pot $1^{-}$strains was digested with Not I (Fig. $3 \mathrm{~A}$ ) and analyzed by pulsed-field gel electrophoresis, the terminal $\mathrm{C}, \mathrm{I}, \mathrm{L}$, and $\mathrm{M}$ fragments of chromosomes I and II were missing, whereas internal fragments were unperturbed (Fig. 3B). Hybridization with gene-specific probes revealed the presence of two new bands corresponding to $\mathrm{C}+\mathrm{M}$ and $\mathrm{I}+\mathrm{L}$, the products of chromosome circularization (Fig.
A

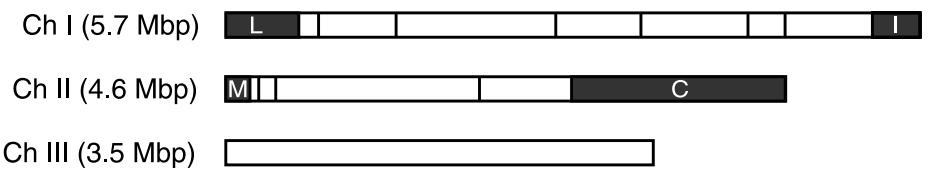

B
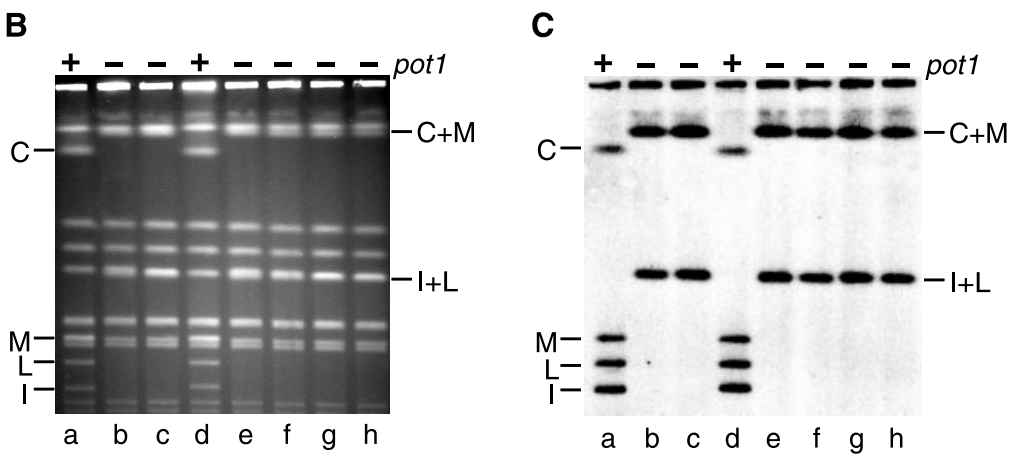

Fig. 3. Pulsed-field gel electrophoresis and detection of terminal fragments. (A) Schematic showing the location of Not I restriction sites on S. pombe chromosomes (41). Only terminal fragments on chromosomes I and II are labeled. (B) Ethidium bromide-stained pulsed-field gel containing Not I-digested DNA from two pot $1^{+}$strains and six independent pot $1^{-}$isolates. Genomic DNA was prepared, Not I-digested, and fractionated by pulsed-field gel electrophoresis as described (34). (C) DNA from the gel shown in (B) was transferred to a nylon membrane and hybridized to gene-specific probes on the $C, I, L$, and $M$ fragments.
A
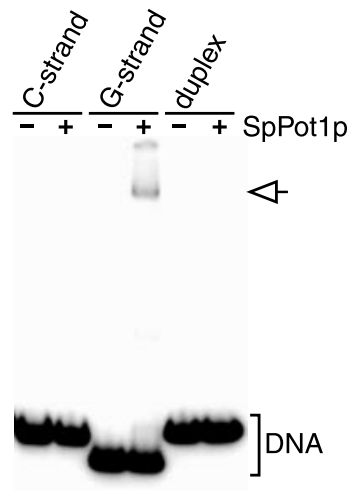

a
B

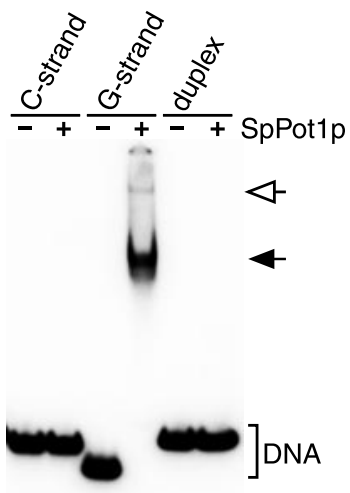

a

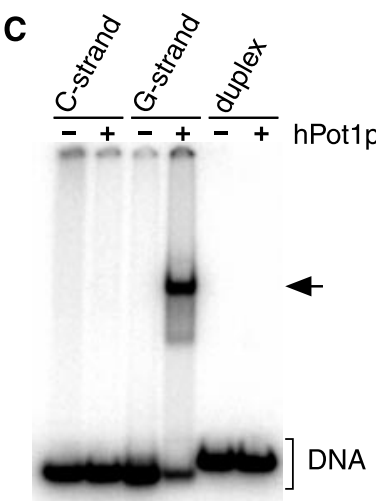

a $\quad b \quad c \quad d$ e $f$
Fig. 4. DNA-binding specificity of SpPot1p. (A) C-strand (CGTAACCGTAACCCTGTAACCTGTAACCTGTAACCGTGTAACC) and G-strand (GGTTACACGGTTACAGGTTACAGGTTACAGGGTTACGGTTACG) were $5^{\prime}{ }^{32} \mathrm{p}$-labeled using T4 polynucleotide kinase and [ $\left.\gamma^{-32} \mathrm{P}\right]$ adenosine triphosphate. Duplex was generated by annealing equimolar amounts of radiolabeled $\mathrm{C}$-strand and unlabeled G-strand. Pot $1 \mathrm{p}(50 \mathrm{ng})$ was incubated with the indicated DNA substrates $(1 \mathrm{ng})$ for $15 \mathrm{~min}$ at $20^{\circ} \mathrm{C}$ in $10 \mu \mathrm{l}$ of $25 \mathrm{mM}$ Hepes (pH 7.5), $1 \mathrm{mM}$ EDTA, $50 \mathrm{mM} \mathrm{NaCl}, 5 \%$ glycerol, and $2.5 \mu \mathrm{M}$ PBoli109 (CCGTAAGCATTTCATTATTGGAAT TCGAGCTCGTTTTCGA) as nonspecific competitor. Complexes were analyzed by electrophoresis at $4^{\circ} \mathrm{C}$ through a 4 to $20 \%$ tris-borate EDTA gel (Invitrogen) run at $150 \mathrm{~V}$ for $80 \mathrm{~min}$. The Pot1p-DNA complex is indicated by an open arrow. (B) Same as (A) except that the added protein (100 ng) contained truncated Pot1p as well as full-length protein. Truncated Pot1p-DNA complex is indicated by a solid arrow. (C) Binding of hPot1p to human C-strand (CCCTAA) $)_{5}$, G-strand (TTAGGG) $)_{5}$, and duplex DNA.
3C). Circularization of all three chromosomes has been found only in $S$. pombe strains that fail to maintain chromosome ends, supporting the conclusion that pot $^{+}$is required for telomere maintenance.

The rapid loss of terminal DNA in pot ${ }^{-}$ strains and the sequence similarity of Pot $1 \mathrm{p}$ with telomere end-binding proteins from ciliated protozoa suggested that Pot1p has a direct role in the protection of telomeres. To investigate whether Potlp binds telomeric DNA, we expressed the protein as a $\mathrm{His}_{6}-$ fusion protein in Escherichia coli (21). In an electrophoretic mobility shift assay, the purified Potlp fusion bound specifically to the G-rich strand of $S$. pombe telomeric DNA, but not to the complementary C-rich strand or double-stranded telomeric DNA (Fig. 4A) (22). The binding affinity of Potlp for telomeric repeats at the $3^{\prime}$ end of an oligonucleotide was greater by a factor of $\sim 5$ relative to its affinity for the same telomeric repeats flanked by nontelomeric sequences (19).

Truncated forms of Pot $1 \mathrm{p}$, resulting from either premature termination or proteolytic degradation, copurified with the full-length protein. The affinity of $\mathrm{COOH}$-terminally truncated Pot1p for DNA was about an order of magnitude greater than that of the fulllength protein (apparent dissociation constant $\sim 10 \mathrm{nM}$ versus $\sim 100 \mathrm{nM}$ ), but the protein retained the same specificity (Fig. 4B). Further purification and analysis by mass spectroscopy showed that the prominent complex (solid arrow in Fig. 4B, lane d) was attributable to the binding of a 22-kD NH -terminal fragment of Potlp. Increased DNA binding has also been observed with the $\mathrm{COOH}$-terminally truncated $\alpha$ subunit of the $O$. nova telomere protein (23), further supporting a functional relationship to Pot1p. Intramolecular inhibitory sequences play a role in modulating the DNA binding characteristics of many transcription factors [e.g., (24)], and a similar situation may pertain to Pot1p.

The identification of related telomere proteins in ciliates and fission yeast prompted us to search for homologous proteins in other eukaryotes. A BLAST search with the $S$. pombe Pot1 protein sequence revealed the product of human cDNA FLJ11037 as the top-ranked match $\left(P=3 \times 10^{-6}\right)$. We refer to the protein encoded by this cDNA as hPotlp (human Pot1 protein). Sequence alignments of hPotlp with the fission yeast and ciliate proteins revealed the highest conservation near the $\mathrm{NH}_{2}$-terminus, where the $S$. pombe and human proteins share 26\% identity and 48\% similarity (Fig. $1 \mathrm{~A})$. Over the same region, the human and $O$. nova protein sequences are $23 \%$ identical and $39 \%$ similar.

Human POT1 mRNA was detected in all tissues examined (25). This finding is consistent with the idea that $h P O T 1$ is a housekeeping gene required to ensure the integrity of chro- 


\section{R E P O R T S}

mosome ends in all cells. In contrast, human telomerase reverse transcriptase mRNA is detected primarily in immortalized and germ line cells, but not in most somatic cells $(26-28)$.

The hPOT1 gene was cloned from ovary cDNA and was found to encode a $71-\mathrm{kD}$ polypeptide. Recombinant hPotlp (with an $\mathrm{NH}_{2}$-terminal $\mathrm{His}_{6}$ tag) was expressed in $E$. coli and purified (29). As with the $S$. pombe Pot1 protein (SpPot1p), a fraction of the hPotlp was lacking COOH-terminal sequences as a result of degradation or premature termination. However, hPotlp produced in $E$. coli showed the same DNA binding specificity as full-length hPotlp from in vitro translation reactions (19). In bandshift assays, hPotlp bound to the G-rich strand of human telomeric DNA (Fig. 4C). In contrast, binding was not observed with the complementary C-rich strand or with double-stranded telomeric DNA.

Telomeric DNA binding by both the $S$. pombe and human Pot1 proteins was unaffected by the presence of a 60 -fold excess of boiled herring sperm DNA and a 2000-fold excess of an oligonucleotide of nontelomeric sequence (19). To further investigate the sequence specificity, we tested whether the G-rich strand of telomeric DNA from different species could serve as a substrate in DNA-binding assays. In a side-by-side comparison, SpPotlp bound the human telomeric sequence less well than it

Fig. 5. Substrate specificity of $S$. pombe and human Pot1p. (A) Binding of SpPot1p to $S$. pombe and human Gstrands (DNA sequences as in Fig. 4). (B) Binding reactions $(10 \mu \mathrm{l})$ contained SpPot1p (50 ng) and radiolabeled $S$. pombe G-strand (15 pg. GGT TACACGGTTACAGGT TACAGGTTAC$\mathrm{AG})$ in the presence of $10-, 100-$, and 1000fold excess of unlabeled S. pombe (G-strand sequence as in Fig. 4A), human (TTAGGG) ${ }_{5}$, or O. nova (GGGGTTTTGGGGT TTTGGGGT) DNA. (C) Binding of hPot $1 p$ to $S$. pombe and human G-strands. (D) Binding of hPot1p to human G-strand under the same conditions as in (B). bound the $S$. pombe sequence (Fig. 5A). In competition experiments, a 1000-fold excess of unlabeled $S$. pombe sequence abolished binding to the radiolabeled substrate, whereas unlabeled human and $O$. nova telomeric DNAs reduced binding by only $\sim 50 \%$ and $\angle 2 \%$, respectively (Fig. 5B). Similarly, hPotlp showed only weak binding to the $S$. pombe sequence (Fig. 5C), which also was not an efficient competitor (Fig. 5D). In contrast, the presence of a 1000-fold excess of the $O$. nova sequence reduced binding to less than $25 \%$. In summary, each protein shows specificity for binding its own telomeric DNA sequence.

Biochemical and structural data have long suggested a role for the Euplotes and Oxytricha telomere proteins in protecting the ends of chromosomes (12). However, as these organisms are not amenable to genetic studies, demonstration of such a capping function in vivo had been lacking. By deleting the $S$. pombe pot $1^{+}$gene, we have now provided evidence that this group of proteins plays a pivotal role in preventing rapid degradation of chromosome ends in vivo. Loss of Potlp led to immediate chromosome instability, whereas the absence of functional telomerase causes gradual telomere shortening over many generations without an immediate effect on chromosome stability and cell viability $(18,26)$. It therefore appears that, at least in $S$. pombe, Pot1p is more important than telomerase for telomere maintenance in the short term.

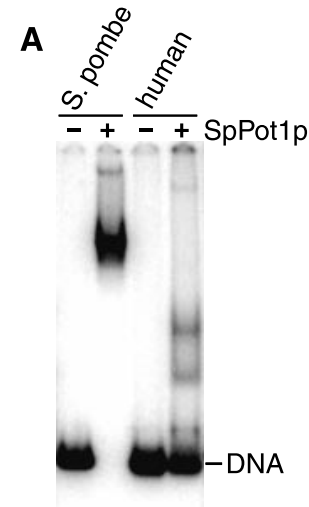

B

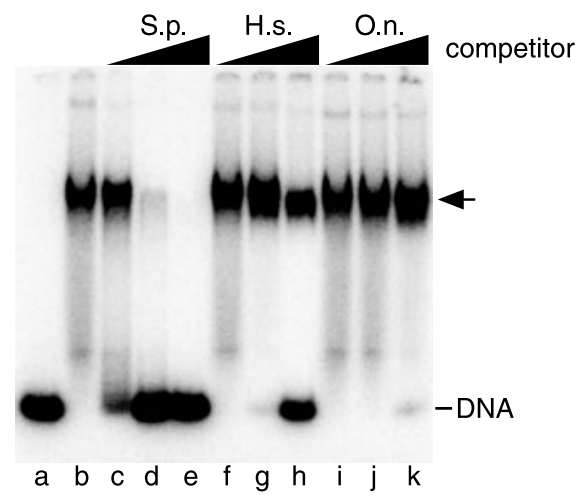

D

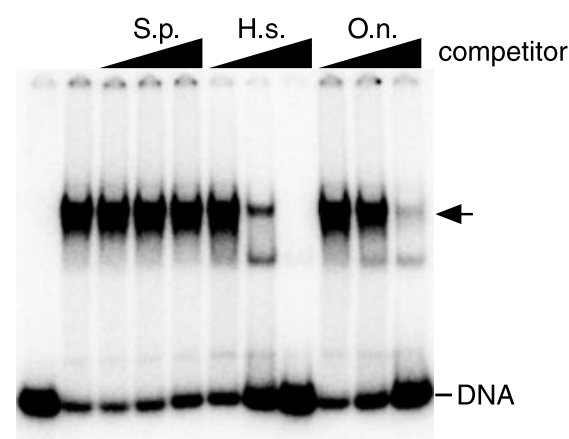

$a \quad b \quad c$ d f g h i j k
In addition, Potlp may be involved in regulating the access of telomerase and/or other enzymes to the chromosome terminus. Reconstitution of the Oxytricha $\alpha-\beta$-telomeric DNA complex prevents extension by telomerase in vitro, consistent with a function for the $\alpha-\beta$ complex in the regulation of telomere length (30). (Note that we have not found an S. pombe or human counterpart to the $\beta$ subunit by homology searching.) In Saccharomyces cerevisiae the single-stranded telomeric DNA binding protein $\mathrm{Cdc} 13$ recruits telomerase to the chromosome end via interactions with the telomerase component Est1p (9). Sequence alignments of Cdc13p with Pot1p and ciliate telomere proteins failed to detect obvious similarities. However, Cdc13p may nevertheless belong to the same family of proteins, because OB (oligonucleotide/oligosaccharide binding) folds, which are seen in the crystal structure of the Oxytricha $\alpha-\beta$-DNA complex and are presumably present in Potlp (Fig. 1B), are identified reliably only by structural analysis and not by sequence homology (31). It will hence be important to probe for interactions between Pot1p and telomerase in $S$. pombe and human cells and to determine whether these proteins fulfill analogous functions to $\mathrm{Cdc} 13 \mathrm{p}$.

It now appears that at least in mammalian cells, telomeres may exist in at least three interconvertible states: as t-loops, Potlp-bound, and engaged with telomerase (32). Although these different states could correlate with particular stages of the cell cycle, they need not be mutually exclusive. As indicated above, Pot1p may be involved in actively recruiting telomerase. Alternatively or in addition, the $3^{\prime}$ end of telomeric DNA could be capped by Pot1p within the structure of a t-loop, which would prevent the chromosome end from being used as a primer for conventional DNA synthesis (33). Now that a key protein that binds at the chromosome end appears conserved across widely diverged eukaryotes, it will be an interesting challenge to determine how it contributes to the various structures and functions of the chromosome end.

\section{References and Notes}

1. L. A. Klobutcher, M. T. Swanton, P. Donini, D. M. Prescott, Proc. Natl. Acad. Sci. U.S.A. 78, 3015 (1981).

2. R. J. Wellinger, A. J. Wolf, V. A. Zakian, Cell 72, 51 (1993).

3. The presence of $3^{\prime}$ single-stranded extensions in $S$. pombe was verified by hybridization of native genomic DNA with a telomeric probe before and after exonuclease I treatment (25).

4. V. L. Makarov, Y. Hirose, J. P. Langmore, Cell 88, 657 (1997).

5. R. McElligott, R. J. Wellinger, EMBO J. 16, 3705 (1997).

6. W. E. Wright, V. M. Tesmer, K. E. Huffman, S. D. Levene, J. W. Shay, Genes Dev. 11, 2801 (1997).

7. B. Garvik, M. Carson, L. Hartwell, Mol. Cell. Biol. 15 , 6128 (1995).

8. E. Pennock, K. Buckley, V. Lundblad, Cell 104, 387 (2001).

9. S. K. Evans, V. Lundblad, Science 286, 117 (1999).

10. D. E. Gottschling, V. A. Zakian, Cell 47, 195 (1986). 
11. J. T. Gray, D. W. Celander, C. M. Price, T. R. Cech, Cell 67, 807 (1991).

12. The $O$. nova $\alpha$ subunit by itself preferentially binds the $3^{\prime}$ terminus of a telomeric oligonucleotide, but also binds single-stranded telomeric DNA internally (11).

13. G. Fang, T. R. Cech, Proc. Natl. Acad. Sci. U.S.A. 90 6056 (1993).

14. M. P. Horvath, V. L. Schweiker, J. M. Bevilacqua, J. A. Ruggles, S. C. Schultz, Cell 95, 963 (1998).

15. W. Wang, R. Skopp, M. Scofield, C. Price, Nucleic Acids Res. 20, 6621 (1992).

16. J. D. Griffith et al., Cell 97, 503 (1999).

17. Heterozygous diploids $\left(\mathrm{h}^{+} / \mathrm{h}^{-}\right.$leu1-32/leu1-32 ura4D18/ura4-D18 his3-D1/his3-D1 ade6-M210/ade6M216 pot $1^{+} /$pot $1:: k a n^{r}$ ) were constructed by replacing the entire ORF of pot $1^{+}$with the kanamycin resistance gene as described (34).

18. T. M. Nakamura, J. P. Cooper, T. R. Cech, Science $\mathbf{2 8 2}$ 493 (1998).

19. P. Baumann, T. R. Cech, data not shown.

20. T. Naito, A. Matsuura, F. Ishikawa, Nature Genet. 20, 203 (1998).

21. The $S$. pombe pot $1^{+}$ORF plus an $\mathrm{NH}_{2}$-teminal His tag and $\mathrm{COOH}$-terminal $\mathrm{V} 5 / \mathrm{His}_{6}$ tag was expressed in E. coli strain M15 ( $p$ Rep4) using tryptone phosphate media. After induction $(0.8 \mathrm{mM}$ isopropyl- $\beta$ D-thiogalactopyranoside) for 6 hours at $24^{\circ} \mathrm{C}$, cells were harvested and resuspended in $50 \mathrm{mM}$ $\mathrm{NaH}_{2} \mathrm{PO}_{4}$ ( $\mathrm{pH} 8.0$ ), $0.1 \mathrm{M} \mathrm{NaCl}, 2 \mathrm{mM}$ imidazole, $10 \%$ glycerol, $0.2 \%$ Tween-20, 5 mM $\beta$-mercaptoethanol, and $1 \mathrm{mM}$ phenylmethylsulfonyl fluoride, to which lysozyme $(0.5 \mathrm{mg} / \mathrm{ml})$ was then added. After $30 \mathrm{~min}$, the concentration of $\mathrm{NaCl}$ was increased to $0.6 \mathrm{M}$, genomic DNA was sheared by sonication, and cell debris was removed by centrifugation. The supernatant was incubated at $4^{\circ} \mathrm{C}$ for 90 min with Ni-NTA resin (Qiagen), which was then loaded onto a column and washed sequentially with $\mathrm{P}$ buffer [50 mM NaH${ }_{2} \mathrm{PO}_{4}(\mathrm{pH} 8.0), 0.6$ $\mathrm{M} \mathrm{NaCl}, 10 \%$ glycerol, $0.2 \%$ Tween-20, and $5 \mathrm{mM}$ $\beta$-mercaptoethanol] containing increasing concentrations of imidazole. Pot1p eluted around $90 \mathrm{mM}$ imidazole. Pot $1 p$-containing fractions were dialyzed against $\mathrm{T}$ buffer $[50 \mathrm{mM}$ tris- $\mathrm{HCl}(\mathrm{pH} 8.0)$, $10 \%$ glycerol, $0.5 \mathrm{mM}$ EDTA, and $0.5 \mathrm{mM}$ dithiothreitol] containing $0.2 \mathrm{M} \mathrm{KCl}$, and Pot $1 p$ was further purified on a Q-sepharose column (Pharmacia) using a linear gradient of $\mathrm{KCl}(0.2$ to $1 \mathrm{M})$. The 22-kD Pot1p fragment was found in the flowthrough, whereas Pot $1 p$ eluted around $0.5 \mathrm{M}$ $\mathrm{KCl}$. The protein was dialyzed against $\mathrm{T}$ buffer plus $0.2 \mathrm{M} \mathrm{KCl}$ and stored at $-80^{\circ} \mathrm{C}$

22. Identical results were obtained when hemagglutinin-tagged Pot $1 \mathrm{p}$ was expressed in $S$. pombe and cell-free extracts were used in bandshift assays (19).

23. G. Fang, J. T. Gray, T. R. Cech, Genes Dev. 7, 870 (1993).

24. J. M. Petersen et al., Science 269, 1866 (1995).

25. See Science Online (www.sciencemag.org/cgi/ content/full/292/5519/1171/DC1).

26. T. M. Nakamura et al., Science 277, 955 (1997)

27. M. Meyerson et al., Cell 90, 785 (1997).

28. A. Kilian et al., Hum. Mol. Genet. 6, 2011 (1997).

29. Human POT1 was amplified by polymerase chain reaction from ovary cDNA and cloned into the PQE30 expression vector. The protein was purified over $\mathrm{Ni}$ NTA resin under the same conditions as SpPot1p. The human protein eluted around $135 \mathrm{mM}$ imidazole.

30. S. J. Froelich-Ammon, B. A. Dickinson, J. M. Bevilacqua, S. C. Schultz, T. R. Cech, Genes Dev. 12, 1504 (1998).

31. A. G. Murzin, EMBO J. 12, 861 (1993)

32. Yet another state may involve a complex with heterogeneous nuclear ribonucleoproteins, several of which have properties consistent with a role in telomere maintenance (35-38).

33. Pot $1 p$ might also bind the displaced single strand of a D-loop within a t-loop, although the protein does have a preference for binding terminal rather than internal repeats.

34. P. Baumann, T. R. Cech, Mol. Biol. Cell 11, 3265 (2000).

35. F. Ishikawa, M. J. Matunis, G. Dreyfuss, T. R. Cech, Mol. Cell. Biol. 13, 4301 (1993).
36. S. J. McKay, H. Cooke, Nucleic Acids Res. 20, 6461 (1992)

37. H. LaBranche et al., Nature Genet. 19, 199 (1998).

38. A. Eversole, N. Maizels, Mol. Cell. Biol. 20, 5425 (2000)

39. G. W. Fang, T. R. Cech, Nucleic Acids Res. 19, 5515 (1991)

40. J. D. Prescott, M. L. DuBois, D. M. Prescott, Chromosoma 107, 293 (1998).

41. J. B. Fan et al., Nucleic Acids Res. 17, 2801 (1989).

42. We thank D. Lyons, G. Mellitzer, T. Nakamura, O.
Peersen, V. Wood, and the members of the Cech laboratory for helpful discussions; D. King for mass spectroscopy; D. Baumann, K. Goodrich, Y. Han, and E. Podell for technical assistance; and T. Bryan, K. Friedman, and A. Zaug for critical reading of the manuscript. P.B. was supported in part by a Wellcome Prize Traveling Research Fellowship (grant 054549/Z/98/Z).

20 February 2001; accepted 11 April 2001

\title{
Relapse to Cocaine-Seeking After Hippocampal Theta Burst Stimulation
}

\author{
Stanislav R. Vorel, ${ }^{1 *}$ Xinhe Liu, ${ }^{2}$ Robert J. Hayes, ${ }^{1}$ \\ Jordan A. Spector, ${ }^{1}$ Eliot L. Gardner ${ }^{3}$
}

Treatment efforts for cocaine addiction are hampered by high relapse rates. To map brain areas underlying relapse, we used electrical brain stimulation and intracranial injection of pharmacological compounds after extinction of cocaine self-administration behavior in rats. Electrical stimulation of the hippocampus containing glutamatergic fibers, but not the medial forebrain bundle containing dopaminergic fibers, elicited cocaine-seeking behavior dependent on glutamate in the ventral tegmental area. This suggests a role for glutamatergic neurotransmission in relapse to cocaine abuse. The medial forebrain bundle electrodes supported intense electrical self-stimulation. These findings suggest a dissociation of neural systems subserving positive reinforcement (self-stimulation) and incentive motivation (relapse).

Cocaine addiction is a chronic brain disorder with psychosocial and neurobiological determinants (1). Treatment efforts are hampered by relapse (2). Imaging techniques have been applied to study the neural substrates of cocaine craving (3-6). These studies, although informative, address subjective craving, not actual relapse. They are correlational, not causal, and they take place in laboratory settings, not the actual context of the cocaine experience. Complementary approaches to mapping brain areas underlying relapse are therefore desirable.

Reinstatement of cocaine-seeking behav-
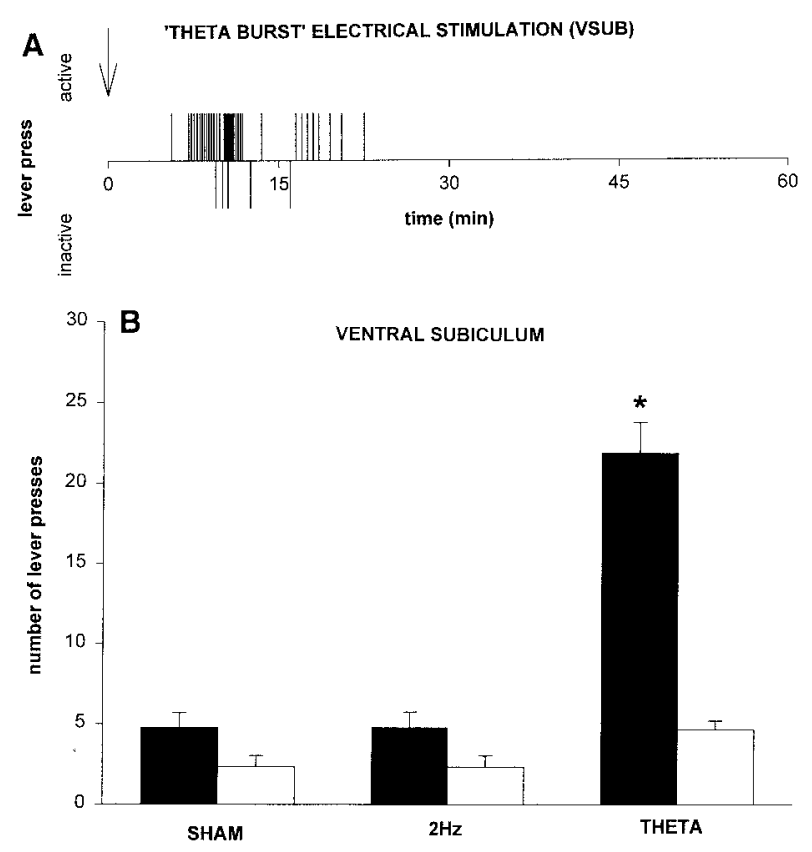

Fig. 1. (A) Effect of VSUB theta burst stimulation (arrow) on reinstatement in an individual rat. Upward bars: active lever presses; downward bars: inactive lever presses. For clarity, only the first hour of the 3-hour session is shown. (B) Effect of different patterns of VSUB electrical stimulation in a group of rats $(n=9)$. The black bars show "active" lever presses (mean \pm SEM), the white bars "inactive" lever presses (mean \pm SEM). During "sham" stimulation, no actual stimulation was delivered. 2 $\mathrm{Hz}$ : $2-\mathrm{Hz}$ repetitive stimulation; THETA: stimulation in "theta burst" rhythm. Asterisk indicates significant difference compared with sham and $2-\mathrm{Hz}$ groups ( $\left.{ }^{*} P<0.00001\right)$. There were no significant differences in inactive lever presses among sham, $2-\mathrm{Hz}$, and theta burst treatment groups. 